\title{
EL EXILIO EN DOS NOVELAS DE MARÍA DOLORES BOIXADÓS
}

JUAN RODRÍGUEZ

GEXEL-CEFID, Universitat Autònoma de Barcelona juan.rodriguez@uab.cat

RESUMEN: El presente trabajo analiza el exilio como tema en las dos primeras novelas de María Dolores Boixadós, Aguas muertas, escrita a principios de los años cuarenta pero no publicada hasta 1970; y Retorno, novela galardonada en 1966 con el Premio Don Quijote y publicada al año siguiente en México por la editorial España Errante. Para ello, el texto describe la situación de la escritora durante la Segunda República y la guerra, las dificultades que afronta, por su condición de mujer y de republicana, su carrera literaria en la España franquista que, junto a su relación con el médico, también republicano, José María Souto Candeira, provocaron su exilio a Venezuela primero y los Estados Unidos después.

PALABRAS CLAVE: Literatura española, narrativa, exilio republicano, Siglo $\mathrm{XX}$. 


\section{EXILE IN TWO NOVELS BY MARÍA DOLORES BOIXADOS}

ABSTRACT: This work analyses exile as a theme in the first two novels by María Dolores Boixadós, Aguas muertas, written in the early forties but not published until 1970, and Retorno, a novel awarded in 1966 with the Premio Don Quixote and published a year after in Mexico by España Errante. To this end, the text describes the situation of the writer during the Second Republic and the war, the difficulties she faced, because of her status as a woman and a republican, and her literary career in Franco's Spain which, together with her relationship with the doctor, also Republican, José María Souto Candeira, caused his exile to Venezuela first and the United States afterwards.

KEY WORDS: Spanish literature, narrative, republican exile, Twentieth century.

a literatura de los exiliados republicanos de 1939 ha estado marcada Lpor una evidente voluntad de testimonio, tanto propiamente en las literaturas del yo como en otros géneros, principalmente en los narrativos. Hay en la obra del exilio, por una parte, un anclaje en el pasado motivado por la nostalgia de la patria perdida, pero también, por otra, la necesidad de explicar lo vivido, para comprenderlo y para confrontar la versión oficial de los vencedores y la desmemoria. La obra narrativa de María Dolores Boixadós no es ajena a esta tendencia, principalmente en sus dos primeras novelas, Aguas muertas y Retorno, tal y como se estudia en estas páginas.

Si bien es cierto que, como consecuencia de su tardía salida del país, a veces se ha cuestionado la condición de exiliada republicana de María Dolores Boixadós, también lo es que ella misma asumió dicha condición, tanto en su vida como en su obra. En realidad, las circunstancias en las que se produce el exilio de los partidarios y defensores de la Segunda República son muy diversas, y la fecha de 1939, de la que se cumple ahora el ochenta aniversario, año de la salida masiva a través, principalmente, de la frontera francesa, no refleja la totalidad de los exilios. Entre esa compleja casuística encontramos la circunstancia de personas, generalmente jóvenes, más o menos comprometidas pero escasamente reconocidas debido a esa misma juventud, que intentan sobrevivir en un primer momento en la España franquista, pero que tropiezan con la censura y la depuración, y acabarán por partir también al exilio, al tiempo que otras vencidas permanecerían en España pese a la represión, como es el caso, por ejemplo, de María Moliner o Josefina Carabias.

Las circunstancias del exilio femenino están, además, inevitablemente teñidas por la cultura patriarcal, que recorre de forma transversal todos los bandos en contienda. Es cierto que la Segunda República permitió la conquista de algunos derechos y dio mayor visibilidad a las mujeres, que, como estudió hace algún tiempo Mary Nash (1999), su participación en la guerra impulsó el avance del feminismo y que la mayor parte de las cabezas visibles de esa revolución dentro de la revolución tuvieron que partir al exilio tras la derrota. También que, a pesar de que en los últimos años la historiografía del exilio republicano ha ido poniendo el foco en la obra de aquellas intelectuales y artistas, estas fueron, como ha señalado Antonina Rodrigo (1999: 19), silenciadas y olvidadas como consecuencia de su doble condición de exiliadas y de mujeres. Menos atención se ha prestado, sin embargo, a las miles de mujeres anónimas, trabajadoras y/o amas de casa que, sin responsabilidad política notoria, en ocasiones incluso con un pensamiento conservador, se exiliaron junto a sus familias, unas veces por conciencia solidaria y otras por la presión del rol que les imponía el patriarcado o por mantener unido el núcleo familiar ${ }^{1}$.

${ }^{1}$ Como ha estudiado Pilar Domínguez Prats, en general, y como consecuencia de la condición subalterna de las mujeres en la España del primer tercio de siglo, en ellas la motivación política no fue prioritaria en la decisión de partir al exilio y predomina la situación familiar o sentimental (Domínguez Prats, 2002: 85-90).

UNED. REI, 7 (2019), pp. 115-151

ISSN 2340-9029 


\section{Algunos datos biográficos}

El exilio tardío de María Dolores Boixadós combina varias de estas circunstancias. Nacida en $1917^{2}$ una familia de la pequeña burguesía de Sort, en el Pirineo catalán, donde su padre era Secretario del Juzgado de Primera Instancia, a los cinco años la madre, católica practicante y que moriría poco tiempo después, decide enviar a María a estudiar en el Colegio María Inmaculada de Tremp, ciudad que se convertirá en escenario de algunas de sus novelas. No duró demasiado Boixadós, quien siempre se ha declarado agnóstica, en el colegio de monjas, pues fue expulsada por rebelde, al negarse a coser y bordar. Acaba la primaria en la academia de la señora Anita, "una maestra extraordinaria" (Alborg, 1993: 156), y estudia música con el señor Mallol, que inspirará el personaje de Mases en su tercera novela, Balada de un músico (1968).

María Dolores Boixadós se confiesa republicana desde muy joven por influencia del tío Campo, esposo de una de las hermanas de su padre con las que vivía en Tremp, e independiente por consejo de otra de sus tías, quien le insistía en la importancia de estudiar para ser libre y no depender de nadie. En las entrevistas ha recordado que era lectora de La libertad, periódico republicano de izquierdas que recibía su tío, y que se alegró mucho de la llegada de la Segunda República.

A los quince años se instala en Barcelona, donde estudia Peritaje Mercantil y acaba el Bachillerato, y donde entabla amistad con Quimeta Comas, catedrática de Historia del Instituto Escuela, quien le abre la puerta al mundo académico e intelectual de la ciudad. También allí vivirá los años de la guerra, instalada ya en la Residencia Ramón Llul, trabajando de secretaria en la Hispano Suiza, que había sido colectivizada por la CNT, y estudiando, gracias a una beca concedida por Antoni M. Sbert, a la sazón director de la Residencia, un año de medicina — una vocación frustradaen la Universitat Autònoma de Barcelona. Con apenas veinte años Boixadós, aunque republicana convencida, no tiene una conciencia política muy

${ }^{2}$ En la entrevista que le hizo Concha Alborg en 1989 Boixadós manifestaba la duda de si había nacido en 1917 o 1919 (Alborg, 1993: 156). Años después, en la entrevista con Varela i Serra, da inequívocamente la fecha de 1917 (Varela, 2005: 150). formada, establece amistad con personas de distintas ideologías y milita, por ser obligatorio para la obtención de la beca, en la Federació Nacional d'Estudiants de Catalunya (FENEC), el sindicato catalanista.

Como consecuencia de la dura represión que, en los primeros momentos de la guerra, ejercieron los comités revolucionarios del Pallars contra los sospechosos de ser quintacolumnistas o reaccionarios (Gimeno, 2018) parece que su tío Campo, a pesar de ser republicano y debido a rencillas personales, tuvo algunos problemas en Tremp y se refugió en Barcelona, donde finalmente fue detenido. Gracias a un compañero de Boixadós, Eugenio Vallejo, delegado de la CNT en la Comisión de Industrias de Guerra, fue puesto en libertad y obtuvo papeles para escapar a Portbou — viaje en el que le acompaña Boixadós- y pasar desde allí a zona rebelde.

Las circunstancias en las que se encuentra María Dolores Boixadós al concluir la guerra, sin embargo, no son del todo claras. En la entrevista con Concha Alborg afirma que fue detenida junto con Quimeta Comas y estuvo un mes en prisión, de donde las sacó Antonio Tovar, amigo de Comas. Regresó entonces a Tremp y, dice Boixadós, tras haber acompañado a un tío suyo al exilio en Montauban, fue denunciada, por lo que tuvo que escapar a Argelia y desde Marruecos regresar a Madrid. Nada de eso explica, en cambio, en la entrevista con Josep Varela, pese a ser una experiencia significativa, sobre todo en una escritora que ya entonces había hecho del exilio temática de sus novelas. En cualquier caso, la decisión de trasladarse a Madrid sí que debió de estar motivada por la necesidad de poner tierra por medio y alejarse de posibles represalias por su militancia estudiantil.

En Madrid Boixadós aprueba unas oposiciones para el Banco de Crédito Industrial y concluye la carrera de Profesorado Mercantil. Al frecuentar el café Gijón, donde iba con una compañera de trabajo, entra en contacto con el grupo de escritores, "de izquierdas y de derechas" que conformaban su tertulia, el grupo Juventud Creadora, lo que despertará su vocación literaria. "Ser mujer en la España de Franco, en Madrid sola, y por añadidura catalana, joven e inquieta, era algo muy difícil", escribe 
Boixadós (Boixadós, 1996: 26). Ser, además, joven escritora en ciernes en un grupo conformado por hombres, no debió de ser tampoco fácil ${ }^{3}$.

En diciembre de 1945 María Dolores Boixadós contrae matrimonio con el fisiólogo José María Souto Candeira. El doctor Souto Candeira, hijo de José Souto Beavís, Director de Sanidad de A Coruña, había sido un destacado estudiante durante la República, becado por la Junta de Ampliación de Estudios para estudiar en Múnich, y había trabajado en el laboratorio de Juan Negrín (Martín Frechilla, 2006: 424). Ricardo Gurriarán, quien añade el dato de que vivió en la Residencia de Estudiantes entre 1931 y 1936, señala su militancia comunista y lo sitúa entre los investigadores "depurados" después de la guerra (Gurriarán, 2006: 217 y 227). También Pilar Cagiao Vila lo menciona entre los republicanos que se exiliaron en Venezuela tras permanecer unos años en España (Cagiao, 2007: 369) y David Simón añade que fue militante activo de la FUE y de las Juventudes Socialistas Unificadas (Simón Lorda, 2010: 270). Según se colige de la información proporcionada por estos investigadores, la sublevación militar había sorprendido a Souto de vacaciones en Santiago de Compostela y ante el peligro de ser detenido y fusilado decidió alistarse en el ejército franquista. En 1939 pudo terminar la carrera en Santiago y se trasladó a Madrid, donde trabajaba en el Instituto de Investigaciones Médicas con el doctor Jiménez Díaz.

El matrimonió se instaló en el barrio de El Viso, donde, según la propia escritora, el doctor Souto atendía gratis a pacientes de escasos recursos, lo que al parecer los hizo sospechosos entre el vecindario (Varela, 2005: 156) y provocó una denuncia (Alborg, 1993: 158). Esa circunstancia, unida al miedo de que afloraran los antecedentes republicanos de ambos, fue determinante para que Souto se decidiera a aprovechar la oferta de la Universidad de Caracas con el fin de que ocupara la cátedra que había dejado vacante por su jubilación otro exiliado republicano, August Pi i Sunyer. De modo que en 1949 María Dolores Boixadós emprende el

${ }^{3}$ No me voy a detener, por falta de espacio, a analizar los avatares de esta primera etapa de la vida literaria de Boixadós ni a analizar sus primeros relatos publicados en revistas literarias, pues poco tienen que ver con su exilio y tengo intención de dedicar a ello un próximo trabajo.

UNED. REI, 7 (2019), pp. 115-15 camino del exilio con varios cuentos publicados y una novela inédita bajo el brazo, en un periplo que le llevará a Venezuela, Estados Unidos y Puerto Rico. La mudanza constante, junto al cuidado de sus tres hijos y los diferentes trabajos que desempeña para contribuir a la economía familiar, dificultarán el desarrollo de su carrera literaria. No en vano la escritora se consideraba parte de una generación "a la que le cortaron la cabeza. Afuera no nos han permitido hacernos mientras que dentro todavía estábamos sin hacer, en el sentido de ser conocidos" (Alborg, 1993: 162).

En última instancia, más allá de las circunstancias que provocaron su salida del país y su traslado a América, lo esencial es que la autora asumirá la condición de exiliada (así lo manifiesta en todas las entrevistas) y que dicha condición se reflejará en su obra literaria.

\section{Aguas muertas}

El nombre de María Dolores Boixadós ha sido eventualmente mencionado en la historia de la literatura por el hecho de haber escrito una novela que quedó finalista de la primera convocatoria del premio Nadal en 1944, la misma que ganaría otra joven escritora, Carmen Laforet. Dejo también para otro momento las circunstancias que rodean el concurso de Aguas muertas en el premio que patrocinaba Destino, no exentas de polémica.

Boixadós había escrito la novela "en quince días" (Alborg, 1993: 158), según recuerda Ignacio Agustí que le explicó, "porque el fenómeno de la guerra civil le había dejado un poso de sentimientos y vivencias que necesitaba explicar de algún modo y aquel era el resultado de ese impulso de sinceridad" (Agustí, 1974: 168). La propia autora reconoce que, "escrita en los años difíciles después de la guerra civil", "fue hecha bajo los mandatos imperativos del corazón. Hay en ella verdad" (Boixadós, 1970: 7). Por circunstancias diversas, entre las que el exilio de la autora tiene un peso importante, la novela permaneció inédita hasta 1970.

No deja de ser sorprendente, por inusual, que el tema del exilio aparezca en la narrativa de Boixadós antes incluso de que se produzca su propio exilio y en una novela de mediados de los años cuarenta, cuando

UNED. REI, 7 (2019), pp. 115-151

ISSN 2340-9029 
incluso la palabra "exilio" era tabú. Hay que tener en cuenta que la novela no llegó a pasar por la censura (cuando se publica en 1970 ya había sido eliminada la consulta obligatoria y habían cambiado las circunstancias políticas), que hubiera más que probablemente tachado con el lápiz rojo no pocos fragmentos de la misma. Sí estuvo, sin embargo, sometida a la autocensura durante el proceso de escritura, provocada por la conciencia de que el tratamiento de determinados temas podía tener consecuencias y reforzada por el pasado republicano de la autora, lo que, sin duda, nos obliga a interpretar la novela entre líneas.

La obra relata la peripecia de una joven alicantina, Elena Just, que se traslada a Madrid para iniciar sus estudios universitarios y se instala en una Residencia femenina durante los meses del curso escolar, argumento que inmediatamente sugiere la comparación con Nada. Pero Boixadós, a diferencia de Laforet, construye un universo mucho más cerrado y exclusivamente femenino, pues los pocos personajes masculinos que aparecen en la novela tienen escaso protagonismo.

Como ya señaló Concha Alborg, la novela, que asimila a la categoría de "existencial"4, se constituye como "una búsqueda de identidad y una indagación de su conciencia como mujer adulta" (Alborg, 1993: 174), como una novela de aprendizaje, pues el propio personaje reconoce al final del texto su transformación tras la experiencia vivida en la Residencia. Elena, que aún no ha cumplido los dieciocho y es, por lo tanto, menor de edad desde el punto de vista legal, procede de una familia de

${ }^{4}$ Alborg utiliza la categoría y la definición que había hecho Gonzalo Sobejano en Novela española de nuestro tiempo (1970). Sin negar el mérito del trabajo del profesor Sobejano, sobre todo en el momento y en las condiciones en que se realiza, me parece que el afán clasificatorio le lleva con frecuencia a un esquematismo que resulta escasamente útil. La socorrida etiqueta de "existencial" intenta aprovechar la emergencia del existencialismo que despunta en Europa desde los años treinta y, fundamentalmente, en la posguerra europea, una filosofía proscrita en la España franquista de los años cuarenta y con la que estas novelas tienen una relación tangencial. En cualquier caso, es lógico que en un país autárquico y racionado, sometido a una dictadura fascista criminal vencedora en una guerra fratricida, con cientos de miles de ciudadanos huidos del país y otros cuantos miles asesinados, la novela tendiera a la introspección en el individuo. pequeños propietarios de Alicante, monárquica y afín a los vencedores, "aunque pasivamente" (Boixadós, 1970: 122), puntualiza la Directora. La guerra, sin embargo, ha hecho mella también en esa familia: a su padre, según le recuerda a Elena la madre en una carta, "le hizo mucho daño moral" y "desde entonces el mundo para él es distinto, aunque asegura que lo entiende mejor" (Boixadós, 1970: 145); la propia Elena, apenas una adolescente entonces, aunque "no había visto ni muertos ni bombardeos ni fabulosas requisas" y el "miedo del miedo de los otros" que sintió "formaba parte del vivir y traía excitación y aventura”, tiene la impresión de que la guerra "parecía no haberse acabado aún" (Boixadós, 1970: 17). También destaca la narradora su "oculta rebeldía” (Boixadós, 1970: 26), el deseo de emanciparse, de estar "menos atada a los lazos familiares", "los deseos de independencia, de poder tomar decisiones por sí sola, de no tener que dar explicaciones de todo cuanto hacía o pensaba" (Boixadós, 1970: 25). Con ese bagaje inicia ilusionada sus estudios en Ciencias Físicas, pues quiere ser astrónoma -carrera poco habitual entonces (y desgraciadamente aún ahora) entre las mujeres, "casi todas a Filosofía y a Farmacia, ipobres chicos!” (Boixadós, 1970: 16)—, pero se encuentra con una Universidad, "gris" y "retrógrada", con unos profesores que "parecen siempre cansados" (Boixadós, 1970: 45).

Recién llegada a una ciudad que no conoce, Elena se incorpora a la Residencia, comandada por un cuadro de la Sección Femenina de Falange. La Directora aparece retratada como un personaje autoritario e inflexible, partidaria de imponer la fe y la moral católicas y de anular la libertad de sus pupilas, y decidirá la expulsión de Elena por la sospecha, fundamentada en un simple rumor, de que pudiera ser lesbiana. Tampoco las compañeras de Elena en la Residencia ofrecen a la protagonista un panorama muy alentador. Se dice explícitamente en el texto que "pocas han vuelto de las de antes de la guerra" (Boixadós, 1970: 16) y la mayoría de las residentes pertenecen a clases acomodadas y a familias de vencedores. Como jóvenes, sin embargo, que son, no necesariamente comulgan con los valores, la moral o las ideas de sus progenitores. Todas se han visto afectadas más o menos por la contienda; para Sara, por ejemplo, fueron tres años perdidos que no sabe "si los he vivido viva, o bien estuve todo el tiempo viviendo muerta...” (Boixadós, 1970: 17); Emilia considera 
truncada su adolescencia y ha perdido "todos los recuerdos", "a no ser una espesa manta de miedo y horror que envuelve todo recuerdo" (Boixadós, 1970: 50); Ágata, probablemente la más rebelde, tiene una pequeña postal del Guernica en su cuarto porque sabe que está prohibido, pero también que ha sido "pintado con amor. Este es el secreto que emociona al contemplarlo. ¡Está prohibido como el amor!” (Boixadós, 1970: 74). Y es ella, sin duda, la que hace el diagnóstico más acertado de la Residencia pues, mientras elogia el sueño que llevó a crear ese tipo de instituciones (la libertad que concede a las muchachas de provincias que van a estudiar a Madrid), desvela el contraste con la realidad actual:

\begin{abstract}
Las dirigentes son en general mujeres premiadas por sus afanes políticos al haber ayudado a los que mandan. No es la mujer preparada, capaz de comprender a las adolescentes, sus problemas, sus preocupaciones, sus preguntas del lugar que ocupan, sus respuestas a las críticas. Ahí está la tragedia, ¡dirección de incapaces! (Boixadós, 1970: 84)
\end{abstract}

Y, cuando Elena le pregunta qué se hizo "de las mujeres de ímpetu, las antecesoras que conquistaron los primeros puestos", Ágata, tras advertirle del daño que le pueden hacer sus compañeras, responde:

No olvides la guerra, Elena... No olvides tampoco que yo me formé en tal dolor. [...] Preguntas por las que tenían corazón y cabeza, ¿cuáles? No sé dónde están... Las que tenían corazón seguramente en sus casas. Las demás vivimos a fuerza de egoísmos y desconocimiento, intentando coger un título, un permiso para ganarnos el pan. ¿Para qué? A la hora de las nueces fracasamos. ¿Es doloroso reconocer que somos regulares en todo y capaces de dejar la profesión, interesadas más por el amor, por tener hijos, por vivir sumisas y seguras? Sí, eso es: el afán de seguridad material, puesto que en nuestra sociedad no tienen demasiado éxito las profesionales. Quizás que los hombres son mediocres..." (Boixadós, 1970: 86-87)

Excepto estas tres, el resto de compañeras le parecen a Elena "hoscas y antipáticas" (Boixadós, 1970: 89), hipócritas y superficiales, pues "hacían solo lo que les pasaba por la cabeza" (Id.: 90), "almas muertas en aguas muertas" (ibidem: 170).

En ese contexto, Elena se aísla del entorno y se refugia en la correspondencia de Juana, personaje que, sin aparecer en la novela más que a través de sus cartas, se alza con buena parte del protagonismo. No es casual que en el momento que Elena castiga a su diario adolescente, en el que expresa su "exceso de amor" sin objeto, enviándolo al cajón porque esos sentimientos le parecen ahora "lejanos, ajenos" (Boixadós, 1970: 27), encuentre tras el mueble el epistolario de Juana, por el cual se obsesiona la protagonista. Elena sucumbirá a la fascinación por una mujer que ha pasado también por la Residencia, pero que ha sabido huir de ella en pos de una pasión. La primera imagen que de ella se hace es la de "un alma en pena arrastrándose de grieta en grieta. Una mujer caminando con fatiga, los cabellos al viento y la mano al corazón, siendo ella más fuerte que el viento" "Juana pecadora, y su cara dolorosa al viento" (Boixadós, 1970: 42); poco a poco irá identificándose con ella, que se convertirá en "su única íntima amiga" (Boixadós, 1970: 58), "la amiga perfecta que ella esperaba", hasta el punto de pensar que "Juana existía en ella" (Boixadós, 1970: 107). Es cierto, como señala Alborg (1993: 173-174), que el romanticismo de las cartas y su deseo de encontrar el amor, junto a su nula experiencia del mismo, ofrecen a Elena un refugio frente al aburrimiento provocado por la vida en la Residencia. No me parece, sin embargo, demasiado descabellado pensar que la atracción que siente la protagonista por la historia de Juana tenga también otras motivaciones, como el interés por la historia de una mujer que ha estado en el meollo del drama que ha desgarrado el país, de una de aquellas mujeres "de ímpetu" que ha sucumbido ante la derrota y el exilio.

Las cartas de Juana van desvelando paulatinamente su circunstancia. No se trata de una muchacha con recursos, pues, a diferencia de las otras residentes, tiene que trabajar para ganarse la vida y ejerce de maestra en un

${ }^{5}$ Como ha señalado Inmaculada de la Fuente, "Las chicas que acudían a la enseñanza superior aprendieron muy pronto a unir dos discursos: el del saber, privilegio todavía de unos pocos, y el de la sumisión femenina, que les afectaba de lleno por ser mujeres" (2002: 46)

UNED. REI, 7 (2019), pp. 115-151

ISSN 2340-9029 
pueblo del Pirineo catalán, una plaza "rechazada por inhóspita por tantas" (Boixadós, 1970: 43). También acerca de ella y su relación con Otilia, la destinataria de las cartas, hubo habladurías en la Residencia, que Sara considera fruto de "envidias": "Se creó así una atmósfera maliciosa sobre su belleza, sus muchos amores, su dudoso talento. Creo haber oído decir que su primer novio salió de España al acabar la guerra” (Boixadós, 1970: 55), dice una de las residentes. La cronología de ese epistolario no es precisa, pero todo parece indicar que la marcha al exilio de ese primer novio, nombrado R. en las cartas, se ha producido cuando "las tropas enemigas, los hermanos enemigos entraban en la ciudad", y aunque el episodio es ambiguo, pues Elena sueña que ella misma es Otilia y Juana, ésta desvela que fue violada por unos soldados y estuvo en la cárcel, donde "perdió un hijo" (Boixadós, 1970: 65).

Desde el primer momento sabemos que Juana espera impaciente noticias de R., que está pendiente de las entradas y salidas de barcos, de aquellos que, a pesar de la neutralidad, han sido hundidos en la guerra mundial, y se queja de que " ¡Retienen tanto tiempo la correspondencia en las censuras!" (Boixadós, 1970: 59). Aunque no sabe exactamente dónde está, ha "viajado con el pensamiento hasta América tantas veces, que ninguno de aquellos inmensos países me sorprendería en el paisaje" (ibidem: 61), y ha mandado noticias a través de "unos amigos que pudieron juntarse a otros familiares en exilio" (ibidem: 62).

Vamos sabiendo también que Juana espera el perdón de R. por una infidelidad que tiene lugar en la inmediata posguerra con G., un hombre casado, personaje que es asimilado a los vencedores y a las clases acomodadas:

...si he confesado alguna vez haber amado a G. era porque las dudas sobre mi lealtad con R. cegaban la razón y deseaba olvidar así a R. Quería sentirme feliz, quería ser feliz con G. [...]. Quise imponerme, obligarme, obedecerme a ser feliz [...]. R. no existía. Pero, ¿qué fuego atormentaba a mi ser? Todo mi apasionado primer amor vivido en R. era una prueba para la pureza que $G$. exigía y merecía. Y así, ¡cómo entender, cómo amar de nuevo, cómo vivir? [...] a pesar de tus duras opiniones debo aclararte que
G. hubiera sido el único capaz de hacerme revivir si conseguía dar la ausencia de R. como no vivida. [...] Debo [...] decirte que hoy estoy contenta de mi doloroso destino y de no haber unido mi vida a G. salvándome de tan cómodo aburguesamiento: la presencia de $\mathrm{R}$. habría venido, a pesar de todos los esfuerzos impuestos por la gratitud, de compañera acomodada, a turbar y llenar de remordimientos mis noches. (Boixadós, 1970: 66)

Si hasta parece ridículo que yo, generación de posguerra, amoral y materializada, pueda estar dominada por una pasión que como sangre rige toda vida. R. es mi sangre que late en un corazón de dolor, de inquietud y de remordimiento. (ibidem: 67)

En la siguiente carta, Juana se niega a ir a Madrid a petición de Otilia. Le dice que responda con evasivas a la Secretaria y a las compañeras que preguntan por ella, que la olviden y se inventa un destino convencional para acallar las suspicacias: “¿Piensan acaso que estoy en otro país? Diles que soy muy feliz, que al final me casé con R., que estoy muy lejos, que tengo un hijo. Toda mujer cree que casarse es la felicidad. Felicidad en la seguridad..." (Boixadós, 1970: 68). Juana prefiere quedarse en las montañas, feliz en sus "irreales encuentros con R.", dejándose morir, pues ha contraído la tuberculosis, e insiste en esa tensión entre el amor al exiliado y el conformismo que imponen los nuevos tiempos:

¿Tú eres quien me acusa de que yo adopte ante esta vida una insobornable cerrazón, ante estos tiempos de entrega externa en que nadie quiere conocerse a sí mismo, en que solo piensan en lo inmediato, en ganancias materiales? [...] Demuestro una vez más ser una inadaptada, jy tú eres la que quieres que frecuente contigo esta juventud nacida de la guerra, preparada con el miedo de sus padres al cinismo y al deseo de querer poseer únicamente, a cualquier precio, bienes materiales?

Encontré y perdí mi pareja y en cambio me resisto a maldecir el infeliz momento en que una venda trenzada de mentiras y de prácticos deseos me apartó de él..." (Boixadós, 1970: 69). 
Juana reprocha a Otilia las ocupaciones intrascendentes, los cines y los bailes, la preocupación por las modas: “¡Qué tonto parece todo! ¡Qué falso suena! [...] Es la sangre corrompida de los muertos lo que ha puesto la tierra morada en nuestra patria, cubriendo todas las conciencias", a las que contrapone el recuerdo de R.: "Alta la frente, alta y distinguida toda la figura, incluso con traje de miliciano” (Boixadós, 1970: 71).

Finalmente, Elena se convierte también en autora de un epistolario dirigido a Juana. Aunque la muchacha vive "más allá de los límites de lo real” (Boixadós, 1970: 116) y en algún momento parece confundirse lo escrito por Elena y las cartas de Juana, en una de estas la maestra revela la recepción de un telegrama en el que R., avergonzado, le comunica que tiene el pasaje pagado para reunirse con él. En ese momento, sin embargo, Juana renunciará a marchar al exilio, pues no puede aceptar "su perdón nacido de una fuente de sonrojo" (Boixadós, 1970: 109). Desvela también que en muchos momentos preparó el equipaje para reunirse con él, aunque enseguida lo deshacía con tristeza "al saber que no tenía destino ni dirección ni lugar geográfico en donde encontrar a R.", y que su negativa a acompañarle estuvo motivada por el deseo de que se sintiera libre, aunque en el momento en que escribe se muestra arrepentida de no haber partido con él:

¿No pudo comprender que ofrecía solamente libre camino a su huida, que no quería ser estorbo en aquel su trágico momento de exilio? ¿No comprendió que le dejaba libre, que libraba a su conciencia de dudas al negarme a seguirle? ¿Que quería que se salvase?... Han pasado los años. Algunos han muerto en el exilio, otros han vuelto, otros se han reunido. [...] Cuando él supo de mí, no quiso entender ni comprender ni perdonar." (Boixadós, 1970: 110)

Hoy sé que debí haberme marchado con R. Que él debió llevarme consigo al exilio, compartir juntos dolores y alegrías, las aventuras que nos hubieran llegado. (Boixadós, 1970: 113)

Todo ello, reforzado por la simbolización que exige una escritura bajo censura, convierte a Juana en un emblema de la España dividida

por la contienda y sometida por los vencedores. Como buena parte de la sociedad del momento, sobre todo entre aquellos que, aun simpatizando con la República, no se habían significado políticamente y no tenían la urgencia de huir para salvar la vida, Juana se debate entre la fidelidad al republicano exiliado, lejano y en paradero desconocido, pero que contiene el recuerdo de aquellos momentos de amor, solidaridad y libertad, y el presente del nuevo régimen totalitario, que obliga a pensar sólo en la supervivencia y empuja al aburguesamiento. Ignorante de esas tensiones hasta ese momento, el descubrimiento del epistolario de Juana supone para Elena una revelación de lo acontecido en el país y de cómo viven los vencidos los efectos de la guerra, en un contexto de opresión que hace revivir sus ansias de libertad: "En el controlado mundo juvenil de la Residencia en el que los sentimientos están sometidos a medida”, señala la narradora, "Elena alimentaba frenéticamente su naciente pasión. Se sentía incómoda entre sus vestidos y ansiaba verse libre” (Boixadós, 1970: 89).

El desenlace de la novela apunta también en esa dirección. Aunque en un primer momento la carta que recibe de su madre, después de que la Directora comunique a esta la decisión de expulsarla de la Residencia, alienta un cambio de conducta y decide quemar las epístolas de Juana, sin embargo sigue poseída "por el demonio de la pasión", incluso en algún momento se le aparece Juana, toma conciencia de que la maestra es "ella misma" (Boixadós, 1970: 182) y decide partir en su busca.

Al final de la novela, Elena se rebela al destino que los demás le quieren imponer (la expulsión de la Residencia y el regreso a Alicante de nuevo con sus padres) y huye, viaja hasta el pueblo del Pirineo donde se encontraba Juana. Espera hallarla en el cementerio, fallecida a causa de su enfermedad, pero la nueva maestra le explica que se ha casado con un médico y se ha marchado a Barcelona. La rendición de Juana, su elección de una vida acomodada frente a la opción del exilio, provoca una cierta decepción en Elena, pero también la despierta de su fascinación. Si en un primer momento piensa en el suicidio, pues "le faltaba Juana, y al faltarle, su vida no tenía objeto", enseguida reacciona pues

...ante sí misma sonaba falsa, lejana, desconocida la idea de la muerte. Se hallaba lejos de la Residencia, tan espiritualmente 
apartada que le parecía que nunca había existido. No había mujeres que se llamaban Directoras, ni Secretarias. Despertaba de una pesadilla, de un sueño que la tenía ungida. Un sueño que la había dormido dolorosamente muchos meses. (Boixadós, 1970: 199)

La huida le ha servido para recuperar la serenidad, "para dar paso a la verdad" (Boixadós, 1970: 201), y, lo que es más importante, la reafirma en la consciencia de lo sucedido y en la necesidad de decidir por sí misma sobre su propio destino:

Ahora era ella de nuevo: ella misma quien vivía. Dependía de ella y de nadie más. Hallada. Crecida. Encontrada a sí misma. Hecha. Todo era conocido y desconocido al mismo tiempo. [...] Todo estaba en sí. Todo vivía explicado. Juana, ¿mentira, ficción sus cartas? ¿Novela? No. Eran verdad mientras las escribía, porque volcaba en ellas su vida, y verdad mientras las vivió ella misma en el cuarto de la Residencia. Y Juana, al impulso del vivir, como una fuente que nace, que crece y que se junta al mar, se había casado. Huyó de su soledad. R. quedó en la región de los sueños, como en la de sus sueños vivía para siempre Juana. (Boixadós, 1970: 202)

\section{Retorno}

\subsection{Una narradora en el exilio}

En 1958 la caída de la dictadura de Pérez Jiménez provoca que Boixadós, que colaboraba con su marido como auxiliar de laboratorio, y Souto pierdan su trabajo en la Universidad de Caracas. Souto recibe entonces una oferta del embajador norteamericano para trabajar para la Comisión de Energía Atómica de los Estados Unidos. Mientras el doctor Souto busca acomodo para la familia, Boixadós y sus tres hijos, nacidos ya en el exilio, hacen un viaje a España y, de regreso a América, se instalan en Oak Ridge, en el Estado de Tennessee. Ese cambio va a ser decisivo en la reanudación de su carrera literaria. Aunque la autora ha afirmado que ella no dejó nunca de escribir, también señala que los “traslados y mudanzas", la necesidad de ganarse la vida y los tres niños dificultaron su tarea creativa y que "las novelas las he escrito limpiando el polvo y criando niños" (Alborg, 1993: 159) ${ }^{6}$. Sin embargo el exilio en Oak Ridge, un lugar regido por el secreto y la sospecha, en una sociedad poco dada a la vida comunitaria, junto al hecho de que Boixadós no hablara inglés, reforzaron, sin duda, la sensación de aislamiento, la nostalgia y la necesidad de comunicarse a través de la literatura.

Surge así, veinte años después de la escritura de Aguas muertas, su segunda novela, Retorno, una obra ubicada ya inequívocamente en el campo del exilio republicano, pues no solo desarrolla esa temática sino que fue galardonada en octubre de 1966 con el Premio Don Quijote de la editorial mexicana España Errante ${ }^{7}$. En esos años sesenta, sin embargo, las circunstancias de aquel exilio han cambiado; se ha desvanecido la esperanza del final de la dictadura y de un retorno colectivo, al tiempo que se producen algunos retornos individuales. La urgencia del testimonio se ha ido, por lo tanto, diluyendo y aunque la memoria sigue teniendo una función importante, se va fusionando con otras temáticas y preocupaciones en ese exilio sin fin, como pueden ser las problemáticas de los países de acogida o la Guerra Fría y la posibilidad de un holocausto nuclear.

Nuevos temas y nuevas formas de narrarlos, que se reflejan también en Retorno. Tanto Concha Alborg (1993: 180) como Laura Vicens (2014: 405) han adscrito la novela a de la categoría de "novela estructural"8

${ }^{6}$ Como ha señalado Josebe Martínez, las actividades intelectuales de las exiliadas "no las eximían tampoco del papel tradicional de amas de casa", lo que, unido a los prejuicios y a las dificultades para profesionalizarse en el campo literario, entorpeció el desarrollo de sus carreras (Martínez, 2007: 33-36).

${ }^{7}$ Boixadós explica que vio la convocatoria en La Estafeta Literaria, lo cual no deja de ser sorprendente, y que "luego ellos lo usaron como polémica contra el exilio". Según parece, intentó publicarla en España, pero que la censura le sugirió que "quitara algunos capítulos" en los que "ataca mucho a la España de Franco", a lo que la autora se negó (Alborg, 1993: 165).

${ }^{8}$ Reitero las dudas sobre la rigidez de esas categorías ya manifestadas páginas atrás. En este caso, además, resulta difícil encajar una novela escrita en el exilio en una categoría concebida para la narrativa creada en España, máxime cuando, como recuerda Fernando Larraz, el propio Sobejano reconocía la "deficiencia informativa" de su libro en lo que a los novelistas del exilio se refiere (Larraz, 2012: 109).

UNED. REI, 7 (2019), pp. 115-151

ISSN 2340-9029 
que definiera Gonzalo Sobejano. Más allá de las etiquetas, lo cierto es que esta segunda novela de Boixadós es, desde un punto de vista técnico, más compleja que Aguas muertas, pues la escritora combina dos planos, dos mundos y dos voces narrativas que se desarrollan de forma paralela en el texto. Además, en consonancia con la emergencia que en esos años tiene en la narrativa americana lo real maravilloso, Boixadós introduce elementos no miméticos en la novela.

Una de esas voces narrativas es extra-heterodiegética y nos explica la vida, sus peripecias e inquietudes, de los habitantes del Pueblo, trasunto de su localidad natal, Sort. Se trata de un narrador omnisciente, que hace uso frecuente del indirecto libre como forma de penetrar en las conciencias de los personajes, desde donde focaliza generalmente el relato de los acontecimientos. La segunda es una narradora intra-homodiegética, un relato diferenciado gráficamente del primero por el uso de la cursiva y en primera persona de una exiliada española que reside en la Ciudad del Secreto ${ }^{9}$, el lugar donde trabajan los científicos y técnicos de la Comisión de la Energía Atómica que experimentan con la fisión del átomo. Dicho personaje, que Vicens describe como alter ego de la autora (Vicens, 2014: $409)^{10}$, vive sola con su hijo y se dedica fundamentalmente a cuidar del niño y a las tareas domésticas.

${ }^{9}$ Con esa denominación se conocía popularmente la ciudad de Oak Ridge, donde se desarrolló el proyecto Manhattan que desarrollaría las bombas que fueron arrojadas sobre Hiroshima y Nagasaki. En los años sesenta, sin embargo, el control militar de la ciudad había aflojado, aunque seguía vigente el secretismo sobre las investigaciones allí desarrolladas; de hecho la propia Boixadós apunta que Souto "hizo un descubrimiento extraordinario" que no ha sido revelado (Alborg, 1993: 160).

${ }^{10}$ La propia Boixadós señala que se trata más bien de un "enganche anecdótico", pues las coincidencias biográficas son escasas: en la novela no hay rastro de marido o compañero alguno del personaje, ni conocemos cuál es su forma de subsistencia, y Boixadós en esos momentos tenía ya tres hijos. La escritora, durante los veinticinco años que vivió en Oak Ridge, estudió Lenguas Romances y Literatura en la Universidad de Tennessee, se doctoró con una tesis sobre Juan Ramón Jiménez - la primera de las dos que hizo, pues en Puerto Rico escribió otra sobre la adaptación de Nazarín que hizo Buñuel- e incluso llegó a dar clases de lengua española y a dirigir el teatro universitario, aunque todo eso fue ya después de la publicación de Retorno, por lo que la novela puede muy bien reflejar, en cierto modo, la soledad de la autora
Esas dos líneas paralelas tienen, sin embargo, líneas transversales que las ponen en contacto en diversos puntos del relato; la primera y más evidente es el hecho de que la mujer que vive en los Estados Unidos es, en realidad, la narradora de las partes de la novela que hacen referencia al Pueblo. Así lo evidencia ya desde el primer capítulo, cuando, tras una panorámica que presenta el lugar desde las alturas de la Roca del Águila, el personaje, mientras prepara una sopa de patatas para su hijo, asume la invención de esa historia:

Soñaba una historia y vi al Pueblo, todos los pueblos que conocí en la España que desde aquí siento como si fuese una inmensa roca granítica agarrada a algo por medio de una punta lengüeteada y flotando sola su inmensa mole en el mar. [...] España flota como un barco a la deriva por toda mi cocina. [...] Mi corazón hecho nido dará vida a los recuerdos jamás abandonados. (Boixadós, 1967: 11)

A lo largo del relato son frecuentes las alusiones del personaje a la acción de "desplegar" el Pueblo, de colocar las casas y los personajes, y dedicarse a observarlos, "para sentirme abrigada cuando la nieve caiga":

Puedo tratarlo como un juguete y ordenarlo en la mesa grande del ancho comedor de América y entonces extraer de mi corazón caliente a sus seres y hablar con ellos, como si todos, aquí y allá y aún más allá, fuésemos solo una gran familia que, sueño mío en este mundo, estuviera unida por la Bondad. (Boixadós, 1967:13)

El relato extradiegético se convierte así en un relato en segundo grado mediante el cual la protagonista conjura su nostalgia por el país del que tuvo que marcharse y en el que proyecta sus ideas sobre el exilio, la reconciliación y el mejoramiento de la especie humana. De hecho, la mayor parte de las historias que la narradora intercala en el relato de su vida en América tienen también alguna vinculación con España, como la de Carmina, su única amiga, que emigra al casarse con un soldado norteamericano y con la que se consuela hablando español; la de

en los primeros años de su vida norteamericana (Alborg, 1993: 160 y 165; Varela, 2005: 162-163)

UNED. REI, 7 (2019), pp. 115-151

ISSN 2340-9029 
Anne-Lou, que viajó a España con una delegación de Átomos por la Paz y que, sin saberlo, "traía una fotografía de la Plaza Mayor, sacada desde la Roca del Águila” (Boixadós, 1967: 40); la del capitán Anderson, que sirvió dos años en España y que vio en un pueblo a una mujer que se llamaba Marieta, otro de los personajes del Pueblo, cargando un haz de leña enorme a la espalda; o, sobre todo, la de un matrimonio de exiliados en los Estados Unidos, con vínculos familiares con el Pueblo, que, a pesar de vivir "con comodidad, casi con lujo", "en lugar de unirse por el recuerdo, en lugar de apreciar los regalos que la vida tan sencillamente aquí les ofreció, se dedicaron a insultarse, a odiarse", a reprocharse mutuamente su exilio; el marido, que se ha cansado de dar clases de español y se ha retirado para "escribir aquellas conversaciones que tuvo con algunos de los que se llamaron dirigentes, allá", un buen día se marcha solo a Florida y allí encuentra "un trozo de España", un viejo monasterio español exiliado como él, donde cree que pueden volver a ser felices (Boixadós, 1967: 73$78)$.

A lo largo de la novela, aunque fundamentalmente en la primera mitad, la narradora y protagonista de esta línea narrativa reafirma de forma recurrente su condición de exiliada y la nostalgia y añoranza de la patria perdida. Recuerda, por ejemplo, tras citar unos versos del poema II de Soledades, la figura de Antonio Machado, al que conoció durante la guerra, o la de Gabriel Miró; las rejas de la Ciudad del Secreto le recuerdan "los campos de concentración" y el Valle de los Caídos mientras lo construían los presos de la guerra (Boixadós, 1967: 79). El contacto con una vecina italiana le alegra, porque por fin tiene una amiga con la que hablar y está segura de que con esas conversaciones "la tristeza del exilio me iría dejando" (Boixadós, 1967: 87). Cuando Carmina, durante una de sus conversaciones, "echa la culpa de su sufrir al estar lejos de su tierra", la narradora le contesta que "puede volver cuando quiera, pues no es exiliada” (Boixadós, 1967: 165), y una frase de la amiga trae a su recuerdo imágenes de su tierra:

Hechos de las calles y de las gentes. Vanidad, intolerancia, provocación [...]. Hablando siempre de Dios y de la Muerte, del Infierno y de la Gloria, del Pecado y del Amor. Y de política y de nuestros malos, por siglos, gobernantes. Y de los que en el exilio sueñan con estos defectos y los idealizan, armonizan, corrigen y superan, hasta creerlos cualidades insuperables. Carmina quiso con una frase recordarme todo y lo hizo. Y me trajo dolor. Me trajo dolor sin traerme esperanza. Y fui entonces como ella, que no inútilmente tenía yo la sangre de la misma raza. (Boixadós, 1967: 167).

También una llamada de Carmina le hace recordar su salida del país, el camino hacia Francia y su primer exilio en Montauban. Y, páginas después, al escuchar una canción que había oído años atrás en Venezuela o en México, aflora el recuerdo de la "España Peregrina", muchos de cuyos nombres "son ya polvo, nube, agua y un nombre en una piedra en los cementerios frente al Caribe y al Golfo", y de su amigo Alberto, al que propuso que escribiera "El libro del héroe de guerra"; pero Alberto quemó "los miles de cuartillas que escribió enardecido", "El humo pudieron respirarlo todos, que la tristeza exilada corre por la sangre y duele para siempre su herida abierta" (Boixadós, 1967: 386), y su renuncia a una épica de la guerra coincide con las posiciones estéticas y éticas de Boixadós:

Alberto no escribía porque las novelas con anti-héroes estaban todas escritas y no quería copiar cambiando nombres, geografías, situaciones y fechas.

A voz en grito para que todos lo oyesen decía: “[...] Descubrí mi incapacidad de describir los horrores de las guerras. Me volví idiota contemplando a los hombres. Tales bestialidades vi que las palabras no existen para contarlas. Debí arrancarme los ojos al verlas. ¿Qué hice? Me replegué como un insecto en su capullo y me volví insensible, mudo, ciego y cobarde. Continúo viviendo cobarde y escribiendo al aire... Pero decidles a los maestros que no enseñen a los niños los libros que hablen de guerra. Que no les inculquen la idea de patria con descripciones de los héroes creados oficialmente. (Boixadós, 1967: 387)

Como ya señaló Laura Vicens (2014: 406), la protagonista de esta parte del relato se halla escindida entre dos mundos, se debate entre 
su añoranza por el Pueblo y el anclaje a América que supone su hijo, la voluntad de "darle patria en donde viva" (Boixadós, 1967: 57), en "mi también América, la de mi hijo, que a ella se lo he dado sin reservas ya que ella me lo ha dado a mí. ¿Qué más quiere de mí América?” (ibidem: 58). La evocación de la patria perdida, el despliegue del Pueblo, la escritura de un relato sobre la vida de sus habitantes le proporciona "olvido y consuelo" (ibidem: 135), la posibilidad de evadirse de América.

Esta contradicción se irá agudizando, principalmente en la segunda mitad de la novela, a partir del momento en que la Hormiga le cuenta las expectativas que han puesto sobre ella, la misión quele tienen encomendada, concienciar a todas las madres del mundo de los cambios que puede producir la radioactividad en la vida sobre la tierra, de la necesidad de evitar una guerra atómica. Resulta significativo que en el momento en que, como le sucede a la Alicia de Carroll, se está haciendo pequeña para entrar en el hormiguero, donde sus nuevas amigas le enseñan las consecuencias de la radiación, tenga visiones del pueblo, casi alucinaciones, y al regresar a su tamaño natural y a su casa el personaje constate que ha perdido los miedos, entre ellos "el de los exiliados muriendo" (Boixadós, 1967: 207) y que la inteligencia "se me estaba haciendo grande" (ibidem: 211). Entra entonces en una fase melancólica derivada de la enormidad de la misión encomendada frente a la escasa confianza en sus fuerzas. Cada vez que intenta refugiarse en el Pueblo, la Hormiga le insiste en que lo olvide y no sufra más por él, que su corazón no está partido, "lo que pasa, y por eso yo estoy aquí, es que tu corazón se hizo grande":

...no debes vivir con tales recuerdos. Estas cosas de aquella guerrita quedaron pequeñas. Ya cada uno apuró su dolor. La injusticia quedará en los libros de historia: allí sabrán que jamás se reconciliaron entre ellos. Esto distraerá a los eruditos futuros, mas a nadie le importa hoy. [...] Entonces, yo tranquilamente le diría:

- Tienes toda la razón, querida amiga. Esto del Pueblo debo dejarlo, pero me distrae, ya que es algo que durante un tiempo amé mucho. (Boixadós, 1967: 304)
Con todo, y a pesar de que la tensión provocada por la dificultad de la misión que le han encomendado deriva en una crisis nerviosa que hará tambalear su entereza e incluso la coherencia del propio discurso, la narradora asume una ampliación de su conciencia que le hace superar la condición de exiliada, la libera de ese sometimiento al recuerdo y la sitúa ante la problemática del presente; que la hace evolucionar, en definitiva, desde una causa perdida del pasado hacia un pacifismo de alcance universal:

Años atrás, cuando la guerra, sufría, sí, pero pensaba y luchaba y cuando veía el odio contagiando a los hombres yo azuzaba su lucha violenta y los crímenes que hacían eran entonces magníficos. ¡Cómo se me iban los días de prisa y de inconscientes derrochando el vivir hasta el fondo!

[...] Yo misma, no me canso de repetirlo, casi tengo olvidada la guerra entre hermanos de mi juventud, así como las muertes violentas por odio y porque sí, por celos y por hambre, por maldad y por afán de mando. Además vi las fortunas cambiar de manos y aprendí que, al fin y al cabo, de esto también se trataba: de esto y del terreno, al que luego se llama patria. El odio tarda más en olvidarse y lo que no se olvida nunca es cuando uno cae esclavo. (Boixadós, 1967: 208-209)

Antes, ¿qué era yo? Antes, con mi Pueblo y mi guerra de juventud, mi añoranza, mi hijo y mis sueños, llenaba mi vida de vigor y violencia. Aquello hoy es ya lejano, sin sentido el recuerdo, sin objeto aquella guerra, que es ya una pálida visión cinematográfica en la pantalla del mundo. Llorar aquellas cuitas, enderezarlas, adorarlas, es trabajo irrisorio. En pocos años el hombre adelantó siglos en el camino de su destrucción. (Boixadós, 1967: 246)

A partir de ese momento ya no tiene necesidad de esconder el Pueblo a las hormigas: "Sin secreto para la Hormiga, el Pueblo y América son uno solo y están juntos ambos en mí. Con el profundo sentimiento de mi deber, no voy escondiendo más las cosas" (Boixadós, 1967: 381). 
El personaje, en definitiva, evidencia la misma transformación que se produce en el mundo y en la literatura del exilio desde el momento en que la posibilidad del retorno se aleja, cuando ese exilio se hace definitivo y las causas que lo provocaron van quedando difuminadas en el tiempo y la historia: la ampliación de la conciencia y la apertura a nuevas temáticas y nuevas preocupaciones, como la guerra fría y el peligro de la destrucción nuclear ${ }^{11}$. Por ello, cuando al final de la novela la narradora empieza a escribir cartas a diversas instituciones y organismos para cumplir con la misión encargada por las hormigas, escribe también al Pueblo, "así, los del Pueblo podrían entender mi transformación en el exilio y el que no quisiera comprender mejor sus propios problemas" (Boixadós, 1967: 366), aunque la respuesta del Pueblo, que alardea del progreso llegado al mismo y del descubrimiento de un yacimiento de uranio, será decepcionante. Y en las últimas líneas de este relato se observa a sí misma con serenidad; ha envejecido prematuramente y se ha quedado sola, pues su hijo "voló al crecerle las alas", pero lo acepta y sigue sonriendo y soñando con la esperanza: "Viví en el exilio desde la juventud a la vejez y vi transformarse el mundo. [...] El mundo se quedó chico en mis manos abiertas, y en mi corazón dormidos los recuerdos" (Boixadós, 1967: 407).

\subsection{El retorno del vencido}

En el otro plano narrativo, el que protagonizan los habitantes del Pueblo, también se hacen patentes los efectos de la guerra y la evocación del exilio. No es casual que el relato se inicie en el momento en que una riada se ha llevado parte del cementerio y ha hecho aflorar los muertos antiguos y el recuerdo de la contienda. Aunque no hay fechas concretas, todo parece indicar que esta parte de la narración se ubica también en los años sesenta; testimonio de ello son tanto las alusiones al desarrollismo y al incipiente turismo, como la existencia de una generación, la de los

\footnotetext{
${ }^{11}$ De hecho la preocupación por la Bomba está presente también en otras obras del exilio, como Caín o una gloria científica (1945) y La bomba increíble (1950), de Pedro Salinas, o Después de la bomba (1966), de Esteban Salazar Chapela (Aznar Soler, 2017)
}

UNED. REI, 7 (2019), pp. 115-15 jóvenes Juan, Luis y Adolfo, que no hicieron la guerra y sólo saben de ella lo que veladamente hablan sus mayores. Boixadós describe los rasgos de una sociedad rural de la montaña catalana, en la que predominan las familias de la pequeña burguesía vencedora que medró con la guerra y la posguerra, fundamentalmente las constituidas por doña Rita, don Emilio y sus cuatro hijas casaderas, que regentan la botica, y la de don Antonio, el sastre recientemente enviudado, y sus cinco hijos, entre los que destaca Juan, apodado "el Mago" por sus habilidades como telépata e hipnotizador y que emigrará a Francia mediado el relato; junto a ellos, las fuerzas vivas: el Juez, el Vicario, el capitán de la Guardia Civil y el Maestro; por encima de todos, don Pablo y Adolfo, caciques del Pueblo.

En lo que a la guerra se refiere, hay un tema recurrente que refleja las preocupaciones de Boixadós: la falta de perdón y reconciliación, que, a la postre, ha dificultado el retorno de los exiliados. El Maestro es consciente de pertenecer a un Pueblo "que cree disfrutar de paz sin todavía haber perdonado al vencido [...]. Sin perdón para el vencido nunca se puede ser de verdad vencedor" (Boixadós, 1967: 23); y también los jóvenes Adolfo y Luis, cuando conversan acerca de lo que han oído sobre la contienda, inciden en este aspecto:

Deshacían en el aturdimiento los misterios de los relatos incomprendidos, ya que parecía que en aquella guerra no quedaron todos los españoles contentos [...]. Lo triste de aquella guerra, lo que la hacía única, era que los problemas por los que pelearon no los había resuelto nadie aún y, lo que era peor y la diferenciaba aún más, era que el perdón y la generosidad fueron los primeros que se contaron entre los muertos. [...] Al Pueblo no había llegado jamás lo que se llama el perdón y los que llamaron a puertas extranjeras estaban todavía allí, dando a cambio del pan su trabajo, y viviendo a añoranzas que era igual que el estar muerto. Lo terrible de aquella guerra fue la falta de generosidad del vencedor. Nunca llegó ni llegará ya el perdón: se hizo demasiado tarde. (Boixadós, 1967: 44-45)

Los muchachos se enfrentan al desconocimiento y al secretismo que todavía rodea a aquella historia. Por un lado "les atraía el recuerdo de 
la última guerra romántica que hubo en el mundo, contada con parcialidad por sus padres"; hablan de ella y llegan "por sí solos a unas conclusiones de lógica aplastante", como que "lucharon a puños y por ideas", según dice Luis; aunque Adolfo matiza: "No la llames romántica. El Maestro dice que sin la reconciliación se convirtió en una guerra de cobardes" (Boixadós, 1967: 46). Incluso don José, el Juez liberal, aunque moderado, que vio su vida truncada por los tres años de guerra, identifica el drama español con la historia de Caín y Abel (ibidem: 121) y evoca la ausencia de justicia durante y después de la guerra:

De Juez hizo el odio: a él no le necesitaron más. El horror se le había vuelto monótono y él, sin juicios, iba a pescar viendo a los soldados que con granadas de mano destruían porque sí, porque era la guerra, las truchas del río.

¿Cómo ejercer el oficio de juez sin libertad? ¿Es que Dios podía haber estado en un solo lado? El día en que él había formulado estas preguntas, el Vicario le había contestado que Dios ordenaba.

La verdad era dogmática y adaptada a las circunstancias. (Boixadós, 1967: 339-340)

El personaje principal, sin embargo, de esta parte de la novela y el que mejor encarna el tema del exilio es, sin duda, el Maestro, que, a juzgar por las coincidencias entre los discursos de ambos personajes, está concebido como portavoz de las ideas de la narradora y también en cierto modo de la autora. Poco a poco vamos conociendo su condición de exiliado republicano que ha retornado a España, a un Pueblo cercano a la frontera francesa que no es su lugar de nacimiento y donde nadie le conocía. El personaje se muestra, empero, desengañado de las ideologías:

A él, como a tantos, le habían fallado al verlas en la práctica, las teorías económicas utópicas y las ideas políticas que ofrecían soluciones al dolor y a la miseria; le habían fallado todas las religiones que predicaban la bondad a través de la sumisión, aceptación y renuncia, pero no fallaba el hallazgo en la naturaleza del cambio moral del hombre. (Boixadós, 1967: 229).

Las ideas políticas le parecían tan insensatamente planteadas que con la práctica de la Bondad caerían todas por su base. (ibidem: 92).

El recuerdo de "aquellos niños salvajes, imitando a los mayores, que él vio en la guerra" y que "obedecieron a la verdad del amor y de la belleza en cuanto éstas se les enseñaron, manchadas aún las manos con la sangre de sus incongruentes crímenes" (Boixadós, 1967: 398), ha motivado su empeño de cambiar, mediante la combinación de educación y selección biológica, la naturaleza moral de sus conciudadanos. Su afición a las ciencias naturales y a la genética le ha convencido de la necesidad de una mutación en el gen moral de los hombres que los libre de la crueldad. Así, cuanto más se cruzasen entre ellos los hombres buenos, "más posibilidades habría de un rápido cambio moral definitivo"; "Día llegaría sin embargo en que harían consciente el hecho de saberse todos iguales y que para cumplir su razón de existencia sería necesario protegerse y cuidarse unos a los otros" (Boixadós, 1967: 91). Esa Misión, piensa, sólo puede llevarse a cabo impulsando un cambio de mentalidad en los niños a través de la educación para evitar que las guerras se reproduzcan, no sólo en España, pues con frecuencia y debido a la porosidad de ambas secciones de la novela se hace también alusión al peligro de destrucción nuclear.

El Maestro justifica, pues, su regreso en la necesidad de ejercer con "niños de españoles, nietos de los que hicieron la guerra", "niños con abono antiguo, para el hombre que sueño y será en el futuro"; no era lo mismo trabajar con los hijos de los exiliados, pues estos sufrían en todo momento la inadaptación y la nostalgia de sus padres, que "en la mesa, a la hora de las comidas, suspiraban por España"; y dado que ellos ya "eran de la nueva tierra, ellos sí, eran aceptados plenamente porque [...] tenían su infancia allí" (Boixadós, 1967: 177), acababan rechazando por cansancio la herencia cultural de sus progenitores:

Regresó al Pueblo porque allí en España entendía todos lo matices de su raza, que a veces se le escapaban en gentes extrañas. Deseaba además que los primeros niños a los que enseñase saliesen de aquel Pueblo que tanto le había hecho sufrir y que a través del sufrimiento le había enseñado a encontrarse. Tenía 
que admitir la necesidad de expresarse en su propio idioma y tenía que volver para enfrentarse de una vez con aquella obligada huida de años atrás. [...]

Desde que había salido de España le faltaba la alegría del alma. [...] Para realizar su misión necesitaba esta alegría y sintió que debía comenzarla allí. [...] Y regresó con fe. (Boixadós, 1967:

92-93)

Esa actitud del Maestro, su comentarios acerca de la guerra, junto a la aplicación de una pedagogía que, sin ser mencionada, alude indirectamente, por su carácter laico y su fundamento en la experiencia directa del alumno, a la de la Escuela Moderna, hace despertar las sospechas de las fuerzas vivas del Pueblo hacia el docente. Él se muestra consciente de que "en cualquier momento podían encarcelarlo", de que podían indagar y descubrir que se trataba de

...un expatriado de guerra, uno de los que la perdieron [...] Indagarían que había vuelto y había encontrado que allí, en el Pueblo, nada había cambiado, nada se había solucionado [...]. Que indagarían y encontrarían que había descubierto que continuaban asustados de pensar, de abrir los ojos, de practicar la generosidad y la reconciliación. Indagarían y encontrarían que sabía que no admitían críticas ni opiniones libres, que querían seguir convencidos, y convencer a la fuerza, de que sus tradiciones y sus razones eran las únicas verdaderas, firmes y poderosas. (Boixadós, 1967: 94)

Las gentes del Pueblo, sin embargo, "parecían entenderle"; aunque algunos, como don Antonio, el sastre, piensa incluso en denunciarlo al capitán de la Guardia Civil, le frena, por una parte, el hecho de que su hija María está aprendiendo mucho con él y, por otra y más importante, la conciencia de la necesidad de superar aquel pasado traumático, pues eso "sería el cuento de nunca acabar, otra vez a la guerra" y concluye que "hora era de acabar y olvidar" (Boixadós, 1967: 108). El Maestro, en su transgresora ingenuidad, está convencido de las "cualidades de bondad y ansias de perfección" de sus conciudadanos y ha sabido ganarse su respeto, respaldado por un "sentido común" que, junto a los años de posguerra en un pueblo fronterizo, "les habían enseñado a callar las más de las veces, que triste era ver y saber de tantas familias separadas" (Boixadós, 1967: 94), aunque también es consciente de que esos buenos propósitos podían cambiar en cualquier momento:

Los que mandan no han perdonado aún. No hay decreto alguno que haya dado el perdón al vencido y yo fui un vencido. ¿Por qué no lo hacen? Nadie lo hará. Todos están cansados. Todos quieren haber olvidado ¿Todos? Cuando vio pasar al Juez y al Vicario pensó cómo fue posible que pudieran haber hecho una guerra entre ellos. Ellos, los representantes de la justicia, la religión y la inteligencia, podían haberse entendido sin guerra... (Boixadós, 1967: 173-174).

El recuerdo de los exiliados está también presente en boca de otros personajes. En una conversación con don Emilio, el boticario don José hace una reflexión acerca de las diferencias entre la emigración, una realidad también palpable en la novela, y el exilio. A decir del Juez, "el que emigra ha perdido para siempre lo que dejó atrás"; en él el recuerdo "opera como un fósil: es una cosa muerta"; no suele volver y si regresa "tiene que hacerlo como un ser nuevo, vivo únicamente en el presente"; el caso del exiliado es, sin embargo, "diferente", pues "el refugiado a la fuerza no se ha ido nunca. Sencillamente ha dejado de vivir aquí". Cuando don Emilio le acusa de estar siempre "de su parte" y pregunta que por qué entonces no regresan, don José acude de nuevo al tema de la falta de perdón y reconciliación:

- ¿Es que alguien los ha llamado? - contestaba y preguntaba a la vez, bajando siempre entonces la voz, don José.

-Claro que no, pero pueden volver. Todo el mundo lo sabe - vociferaba sin disimulo su padre ${ }^{12}$.

- Nadie los espera - la voz de don José se ponía triste y calmada. (Boixadós, 1967: 120)

\footnotetext{
${ }^{12}$ En referencia a las hijas que escuchan la conversación y desde cuyo punto de vista se narra el episodio.
}

UNED. REI, 7 (2019), pp. 115-151

ISSN 2340-9029 
Y ambos acaban coincidiendo en que "parecía imposible" ese retorno:

Sabían muy bien - continuaban expresando- que nunca, en todos aquellos años, se habían abierto los brazos a los que, viviendo fuera, nunca se habían ido: “Olvidemos. Razón unos, razón otros. Todos perdimos hijos. Os necesitamos porque entre todos tenemos que hacer de nuevo a España. Venid y sujetad los brazos que se nos van, que los emigrados no vuelven nunca”. (Boixadós, 1967: 121)

A lo largo de la novela el Maestro va recordando también su peripecia en el exilio. Se había instalado, en un primer momento, en Argelès-Gazost, en el Departamento de Hautes-Pyrénées, próximo a la frontera con España y a la localidad de Lourdes, que aparece mencionada en varias ocasiones en la novela; unos años que define como "difíciles" pues allí "todos esperaban volver. Y aquella gente no quiso ir más lejos y nadie pudo arrancarlos de cerca de la frontera con la esperanza de volver" cuando acabara la guerra europea; "Y las almas se iban mustiando y la segunda guerra mundial los olvidó y él y otros se fueron más lejos" (Boixadós, 1967: 175).

Pasó a Inglaterra y luego residió unos años en un país de Sudamérica que no especifica - aunque en un momento de la novela se menciona México (Boixadós, 1967: 263)—, donde con su amigo Pedro asistía los sábados a las comidas de

...los republicanos españoles y que reunían a un grupo de intelectuales de la España Peregrina, cada uno de ellos [...] con la necesidad de ganarse la vida y usar su talento y sus brazos peregrinando en la sociedad extraña. Pero los sábados, en el restaurante, pedían las más inverosímiles comidas españolas, renegaban y hablaban, gritaban y peleaban, discutiendo todo como celtíberos enjaulados. Así liberados, con el necesario desahogo de la raza y con puros habanos en la boca, regresaban a sus casas y a sus familias para ver la manera de vivir y de ganar dinero $[. .$.$] perdida en el fondo de su corazón la esperanza de$ regresar jamás a España como una unidad de españoles libres.

(Boixadós, 1967: 231-232)

Pedro y el Maestro fueron, sin embargo, alejándose de los grupos del exilio que "iban empequeñeciéndose, divididos. La muerte y la vejez eran los primeros desertores" (Boixadós, 1967: 232), y, vencido por la nostalgia y el "miedo a morir lejos de España" (ibidem: 175), el Maestro acabará regresando a Argelès para estar más cerca de su país. Allí encuentra a todos los compañeros envejecidos, temiendo morirse antes de que los dejaran entrar "como en nuestra casa, de par en par las puertas, como a españoles, que nos dio vida España” (Boixadós, 1967: 175-176), y cuando le preguntan por qué no se ha quedado en América, responde que no desea “pertenecer a nadie. Solamente participo de la vida. Respiro aire”. En el presente narrativo, imbuido en su trabajo, el recuerdo de ese exilio "va haciéndose historia. Y la historia hay que contarla, claro que sí. La historia es lección cuando se cuenta la verdad" (Boixadós, 1967: 176).

Regresa, pues, para no sentirse nunca más desarraigado y para cumplir con su sueño, con su Misión, y para dejar de lado la nostalgia y pasar a la acción transformadora, aunque sea a través de una humilde labor docente. En ese sentido, también esta parte del relato reflexiona acerca de la responsabilidad del individuo. Resulta, a este respecto, significativo el relato que hace de su retorno, cómo tomó el camino del sur y "al cruzar la frontera por las altas cumbres vio que el aire no se rompía y que era el mismo a un lado y al otro", y fue como "un nuevo nacimiento" (Boixadós, 1967: 322). Unos amigos en el exilio le habían indicado el punto en el que enterraron las armas con las que habían combatido al fascismo; cuando el Maestro levanta la piedra bajo las que están enterradas le planta cara un alacrán; piensa en matarlo pero "de súbito tuvo la misma sensación de angustia y desamparo que le invadió el día que en Madrid disparó en el frente el primer tiro contra un hombre"; decide entonces que no va a entrar en su patria matando, ni siquiera a un alacrán, y, como le sucede a la narradora del relato paralelo, la guerra de su juventud le queda en ese momento "lejana y pequeña", y aquellas armas "reliquias [...] frente a las inventadas por desintegración y fusión nucleares que el hombre había hecho proliferar en los últimos años" (Boixadós, 1967: 323):

UNED. REI, 7 (2019), pp. 115-151

ISSN 2340-9029 
La revelación de su misión [...], habían hecho crecer su sentimiento de patria hasta que ésta se había convertido en el mundo. Regresó sin entender muy bien por qué impulso lo hacía. Había dejado en otras tierras a cientos de miles de los que, como él, un día habían salido tristes y pobres hacia un forzado exilio. Todas aquellas gentes en el fondo de sus corazones soñaban con el regreso e idealizaban la patria hasta el extremo de que sus defectos no existían y de que ni siquiera existían las tristes verdades que los tenían fuera de ella, adornadas con el perfume del amor y de la nostalgia.

Al volver comprendió para siempre que podía regresar y vivir en cualquier parte del mundo, seguro de que ya nunca más la angustia y el deseo de aquella geografía volvería a perturbarle profundamente. (Boixadós, 1967: 325)

En términos semejantes se expresa también al recibir las cartas de su amigo Palacio que, en su exilio americano, permanece anclado en la añoranza de la patria y en las posiciones que antaño le obligaron a abandonarla, sentimientos que cultiva "con mimo y nostalgia", pues "es como una enfermedad incurable en mí hasta mi muerte" (Boixadós, 1967: 278). Hay, además, en sus palabras un cierto reproche al Maestro por su regreso, por haber transigido, por haber vuelto solo y casi de forma clandestina, sin esperar a la posibilidad de hacerlo "juntos, en una unidad y con la cabeza alta" (Boixadós, 1967: 280). Este, que "conoce bien, por propia experiencia, cómo en el exilio las cosas se idealizan hasta más allá de la razón y de la realidad" (Boixadós, 1967: 278), renuncia, sin embargo, a contestar a las carta, pues le resulta difícil explicar las razones de su retorno, su necesidad de trabajar en su Escuela para que "estas vuestras conquistas sean permanentes" (ibidem: 280), de impulsar la inteligencia que conduzca "a un cambio hacia una Bondad Activa” (ibidem: 282), más necesaria que nunca ahora que la humanidad se enfrenta al peligro de su destrucción total.

Palacio representa, pues, ese exilio que se va disgregando y muriendo, mientras ve cómo los hijos se aclimatan a las sociedades de acogida. Aunque los años transcurridos le han convencido de que "lo pasado, pasado está y enterrado debería estar para siempre”, y los años de destierro le han enseñado "a ser tan generoso que mi espíritu ha crecido hasta el extremo de estar libre y de desear solamente lo bueno para todos", la herida por la que sangra es, precisamente, la ausencia de una verdadera reconciliación:

Pero lo que me aqueja y desorienta es que sin decirnos de otra manera, ya que nada hay que perdonar: "España os espera”, no me encuentro con ganas de subir al cielo. Es que ya te dije, Maestro, que dejé el corazón en un rinconcito, debajo de una morera, y que reclamo volver a buscarlo con las puertas abiertas de par en par, para que cuando me entierren, me entierren completo. (Boixadós, 1967: 394-395)

El Maestro, por el contrario, opta por no esperar ese desenlace que le parece poco probable y por llevar a cabo una acción, aunque pequeña en un pequeño pueblo y en cierto modo utópica, positiva para la transformación de la humanidad. Proyecta construir, con el dinero que le proporcionó la venta del cortijo que heredara de sus padres, una Escuela nueva en el Pueblo, aunque sea a costa de quemar el castaño carcomido por las termitas en el prado donde va a levantarla, una purificación que considera necesaria. Y aunque lleva un tiempo ya enseñando a los niños del pueblo y su proyecto empieza a ser realidad, encontrará al final de la novela el verdadero sentido a su retorno cuando, paseando junto al río que se llevó la vida de Adolfo y donde "años atrás, durante la guerra, otras vidas habían sido arrojadas por el odio” (Boixadós, 1967: 403), ve que Marieta, a la que Adolfo, el hijo del cacique, había dejado embarazada, intenta ahogar a su hijo recién nacido. El Maestro lo saca del agua, lo devuelve a la vida y se ofrece como padre, al tiempo que su felicidad crece: "Por eso regresó, piensa, por eso tuvo que regresar. Tuvo que regresar aunque fuera solo para arrebatarle aquella vida al río" (ibidem.: 404).

\section{Conclusiones}

Los dos textos analizados evidencian hasta qué punto María Dolores Boixadós asumió su condición de exiliada. Si bien su compromiso durante 
la Segunda República y la guerra fue poco activo y pudo permanecer, sin que su vida peligrara, en España durante la primera posguerra, como mujer y republicana vio dificultado el desarrollo de su carrera literaria en aquellos difíciles años, reflejados en su primera novela, Aguas muertas, un texto que, pese a quedar finalista de la primera edición del Premio Nadal, no vería la luz hasta veinticinco años después. La novela refleja el despertar a la vida y a la historia de una joven estudiante en los primeros años de la posguerra, a partir del hallazgo fortuito del epistolario de una joven maestra republicana cuyo gran amor ha tenido que partir al exilio. De ese modo, el inconformismo inicial que manifiesta Elena, la protagonista, frente a un entorno autoritario y dogmático como el de la Residencia se verá nutrido por la historia de Juana hasta llevarle a la rebelión contra el destino que la familia y la sociedad patriarcal le han impuesto.

Más allá de estas simpatías republicanas, fue, sin embargo, su matrimonio con el doctor Souto Candeira, que había militado activamente en la JSU y la FUE, y el miedo a las represalias los que la condujeron al exilio, como sucedió con tantas mujeres que, sin una implicación directa y visible en la defensa de la República, acabaron huyendo con sus familias. Boixadós, a diferencia de muchas otras, optó sin embargo por dar visibilidad, a través de la escritura de Retorno, su segunda novela, a la problemática de esas mujeres y del exilio en general. La obra se desarrolla en dos planos complementarios y presenta, en el primero de ellos, a una mujer exiliada en los Estados Unidos que ha hallado en la nostalgia hacia su Pueblo un refugio frente a la soledad y el desarraigo, pero que al mismo tiempo se verá empujada por las hormigas a iniciar una campaña para concienciar de los riesgos de la energía nuclear. En el otro plano, relato en segundo grado de la mujer exiliada, se narra la vida en el Pueblo en la década de los sesenta, donde destaca la figura del Maestro, un exiliado que ha retornado a España con la idea de dejar atrás viejos enfrentamientos y trabajar por la reforma moral del país.

Si Aguas muertas refleja la fascinación, reforzada por la represión y la ocultación que impuso la dictadura, que las jóvenes de la inmediata posguerra pudieron sentir frente a la historia que aquellas mujeres republicanas que habían abierto múltiples caminos que ahora les cerraba el franquismo, Retorno plantea, en los años sesenta y con la prolongación indefinida del exilio, la necesidad, no de olvidar, pues no hubo ni perdón ni justicia ni reparación, sino de superar las viejas batallas para enfrentarse, desde una mirada femenina, a las nuevas urgencias que apelan a la responsabilidad del individuo, como la necesidad de combatir la proliferación nuclear y la violencia.

Recibido: $13 / 06 / 2019$

Aceptado: 05/11/2019

\section{Referencias bibliográficas}

Admella Severiano, Maria y Antonieta Profitós Soldevila (2015-2016), Maria Dolors Boixadós: Una dona pallaresa avançada al seu temps, Tremp. Disponible en: http://www.fundaciocarulla.cat/en/premis-baldiri-reixac/ bones-practiques/maria-dolors-boixad\%C3\%B3s-una-dona-pallaresaavan\%C3\%A7ada-al-seu [consulta: 14/03/2019].

Agustí, Ignacio (1974), Ganas de hablar, Barcelona: Planeta.

Alborg, Concha (1993), "María Dolores Boixadós; entrevista” y "María Dolores Boixadós: una escritora transterrada”, en Cinco figuras en torno a la novela de posguerra: Galvarriato, Soriano, Formica, Boixadós y Aldecoa, Madrid: Ediciones Libertarias, pp. 155-170 y 171-198.

Aznar Soler, Manuel (2017), "La bomba atómica, un dilema moral entre ciencia y política en Caín o una gloria científica, de Pedro Salinas", en Susanne Hartwig (ed.), Ser y debe ser. Dilemas morales y conflictos éticos del siglo XX vistos a través de la ficción, Madrid / Frankfurt: Iberoamericana / Vervuert, pp. 257-277.

Boixadós, María Dolores (1967), Retorno, Oaxaca: España Errante.

--- (1970), Aguas muertas, Madrid: Ediciones Punta Europa. Disponible en: https://es.slideshare.net/JulioPollinoTamayo/aguas-muertas-1944mara-dolores-boixads-96539379 [consulta: 14/03/2019]. 
--- (1996), "Sin poder ni saber escribir verdades", Suplemento Cultural de $A B C, 26$ de julio, p. 26

--- (2010), Balada de un músico, Tremp: Garsineu Edicions.

Cagiao Vila, Pilar (2007), "Outra vez America, terra de acollida”, en Actas do Congreso Internacional "O exilio galego", Santiago de Compostela / Sada: Consello da Cultura Galega / Arquivo da Emigración Galega / Ediciós do Castro, pp. 352-376. Disponible en: http://consellodacultura. $\mathrm{gal} / \mathrm{mediateca} /$ extras/CCG_2001_Actas-do-congreso-internacional-OExilio-Galego.pdf [consulta: 14/03/2019].

Domínguez Prats, Pilar (2002), Mujeres españolas exiladas en México (19391950), Tesis Doctoral, Madrid: Universidad Complutense de Madrid.

Fuente, Inmaculada de la (2002), Mujeres de la postguerra, Barcelona: Planeta.

Gimeno, Manuel (2018), Revolució, guerra i repressió al Pallars: 1936-1939, Tremp: Garsineu.

Gurriarán, Ricardo (2006), Ciencia e conciencia na Universidade de Santiago (1900-1940): do influxo institucionista e a JAE á depuración do profesorado, Santiago de Compostela: Universidade de Santiago.

Larraz, Fernando (2012), "El lugar de la narrativa del exilio en la literatura española”, Iberoamericana, 47 (septiembre), pp. 101-113.

Martín Frechilla, Juan José (2006), Forja y crisol. La Universidad Central, Venezuela y los exiliados de la Guerra Civil española 1936-1958, Caracas: Universidad Central de Venezuela / Consejo de Desarrollo Científico y Humanístico.

Martínez, Josebe (2007), Exiliadas. Escritoras, Guerra civil y memoria, Barcelona: Montesinos.

Nash, Mary (1999), Rojas, Las mujeres republicanas en la Guerra Civil, Madrid: Taurus.

Rodrigo, Antonina (1999), Mujer y exilio 1939, Madrid: Compañía literaria.
Simón Lorda, David (2010), "Os nomes do exilio (médico, republicano, galego)", Cadernos de Atencion Primaria, 17, pp. 264-270.

Sobejano, Gonzalo (1975), Novela española de nuestro tiempo (en busca del pueblo perdido), Madrid: Prensa Española.

Varela i Serra, Josep (2005), “Maria Dolors Boixadós i Servat”, en Memòria de Lleida, Lleida: Pagès Editors, pp. 147-166.

Vicens Vega, Laura (2014), "Visión del regreso en Retorno, de María Dolores Boixadós", en Manuel Aznar Soler, José-Ramón López García, Francisca Montiel Rayo, Juan Rodríguez (eds.), El exilio republicano de 1939. Viajes y retornos, Sevilla: Renacimiento, pp. 404-411. 